\title{
ethic@ \\ CONTRA UMA MORALIDADE DAS MULHERES: A CRÍTICA DE JOAN TRONTO A CAROL GILLIGAN
}

\author{
AGAINST WOMEN'S MORALITY: JOAN TRONTO'S CRITICISM TO \\ CAROL GILLIGAN
}

\author{
LETÍCIA MACHADO SPINELLI ${ }^{1}$ \\ (UFN, Brasil)
}

\begin{abstract}
RESUMO
Esse artigo pretende reconstruir a crítica de Joan Tronto ao modelo da ética do cuidado de Carol Gilligan. A análise de Tronto compreende, por um lado, que o cuidado não se restringe a uma moral feminina, mas é possível verificar sua prática em grupos em condição de subordinação, e, por outro (em consequência disso), que não se pode teorizar o cuidado sem o aporte do social. Sob esse aspecto, Tronto observa na análise de Gilligan um discurso essencialista e elitista que pretende universalizar a experiência do cuidado a partir de grupos hegemônicos.

Palavras-chave: Cuidado; Ética; Gênero; Desigualdade
\end{abstract}

\begin{abstract}
This paper aims to reconstruct Joan Tronto's critique of Carol Gilligan's model of care ethics. Tronto's analysis comprises, on the one hand, that care is not restricted to a feminine morality, but a morality of groups in the condition of subordination, and, on the other hand (consequently), that one can not theorize care without social contribution. In this aspect, Tronto observes in Gilligan's analysis an essentialist and elitist discourse that seeks to universalize the experience of care from hegemonic groups.
\end{abstract}

Keywords: Care; Ethics; Gender; Inequality

Introdução

Joan Tronto compõe o núcleo de teóricos que, a propósito da ética do cuidado, não procura simplesmente rejeitá-la, mas em repudiando uma certa estrutura reflexiva já arraigada, intenta a sua reformulação. Segundo Tronto, o alcance e profundidade de uma ética do cuidado carece da especificação da associação entre o social e o filosófico, caso contrário, a ética do cuidado se torna o assunto de algumas "mulheres mal informadas" (TRONTO, 1987, p. 11). Tronto chama atenção no sentido de que é necessária uma melhor apreciação do contexto social e filosófico da ética do cuidado, a fim de evitar que essa teoria seja compreendida como uma teoria de alcance limitado e base teórica frágil, como algo que diz respeito à algumas mulheres 
mal informadas, as quais, pode-se especular, se identificam como aquelas não se saíram bem no âmbito da ética da justiça e por isso buscaram a ética do cuidado ${ }^{2}$.

Embora defenda a importância da categoria "gênero", a análise de Tronto pretende destacar a pertinência do cuidado enquanto uma teoria que não pode ser pensada fora do perímetro do aporte social, em que se busca destacar outras intersecções que marcam as vivências dos indivíduos. A investigação da autora pretende, portanto, se constituir como uma alternativa crítica ao modelo do cuidado apresentado por Gilligan.

Na proposição de seu modelo político de cuidado, o qual coincide com a sua crítica endereçada à Gilligan, o ponto fundamental para entender a verve reflexiva de Tronto e que configura enfim a sua análise política do cuidado, centra-se no fato de que a ética do cuidado (na forma do que Gilligan denominou de voz diferente) é pressuposta não apenas vinculada as mulheres, mas a grupos não-hegemônicos em geral. Ou seja, Tronto não restringe o cuidado ao gênero, mas também a outras condições de subordinação, alargando, assim, a conceptibilidade do cuidado para questões de cunho social que, embora englobem, transcendem o gênero.

Seguindo o intento de apresentar a crítica de Tronto a Carol Gilligan, assim como o potencial teórico de sua análise sobre o cuidado, o texto que segue se edifica nos seguintes termos: primeiro, apresentar a ética do cuidado segundo Carol Gilligan, seguindo o padrão do que denomina de voz diferente e, expor (ainda que minimamente) algumas críticas que lhe são habitualmente dirigidas. Em seguida, pretende-se reconstruir a crítica de Tronto a Gilligan em que se destacam dois pontos: por um lado, a fragilidade do argumento de Gilligan no que tange à voz diferente enquanto uma voz das mulheres, destacando que se trata de uma postura moral inerente a grupos não hegemônicos, e, por outro, o essencialismo e elitismo que permeiam a posição de Gilligan considerando quer a percepção engessada da mulher a partir do paradigma do cuidado quer a homogeneização da experiência das mulheres em geral sem considerar as intersecções que atravessam a vivência de cada uma. Por fim, é preciso deixar claro, que o texto tem a pretensão de apresentar a crítica de Tronto à Gilligan seguindo o argumento de Tronto de modo fiel, de maneira que, nesse momento, não se dedica a "criticar a crítica" de Tronto, mas apenas reconstruí-la de modo fidedigno.

\section{I - Cuidado e gênero: a voz diferente de Carol Gilligan}

Embora a questão do cuidado seja hoje tratada a partir de matrizes teóricas distintas e variadas, é inegável que sua noção embrionária e mais afamada se situa na obra In a Different 
Voice: Psychological Theory and Women's Development de Carol Gilligan publicada em $1982^{3}$. Ao tratar da voz diferente, Gilligan polariza a compreensão moral em duas abordagens: a primeira, hegemônica e tida como voz padrão, se orienta pela justiça, o respeito aos direitos individuais e normas universais; a segunda, chamada voz diferente, opera sob o signo da manutenção dos relacionamentos, da empatia e do altruísmo. A primeira abordagem caracteriza a ética da justiça enquanto a segunda se identifica com a ética do cuidado. A ética da justiça configura uma abordagem caracterizada por um aporte abstrato, com forte apreço à racionalidade e neutralidade, configurando um sujeito atomizado. Sua caracterização está em comunhão com estereótipos masculinos. A ética do cuidado, por sua vez, se caracteriza por uma abordagem contextual, reforça o papel das emoções e favorece a importância das impressões subjetivas, consolidando um sujeito definido pela conexão que se identifica com as características que a cultura ocidental atribui ao feminino. As "vozes" conduzem, enfim, para duas maneiras de falar sobre os problemas morais, dois modos de conceber a intersubjetividade na relação eu-outro.

A tese de Gilligan desenvolvida em In a Different Voice: Psychological Theory and Women's Development guarda a sua ideia embrionária na crítica feita pela autora à teoria do desenvolvimento moral de Kohlberg. No texto In a Different Voice: Womens's Conceptions of Self and of Morality (1977), Gilligan observa que a teoria do desenvolvimento moral de Kohlberg é eivada de percepções que refletem a experiência masculina, ocultando as experiências das mulheres na esfera moral. O que a tese de Gilligan propõe se concentra na investigação das experiências morais de homens e mulheres em que se conjugam, por um lado, questões de cunho metodológico, traduzidas pela exclusão das mulheres das análises do desenvolvimento moral, e, por outro, questões de cunho teórico, eclipsadas pela supremacia de características identificadas com o masculino. Dentro dessa conjuntura epistêmica, Gilligan pretende reabilitar ou pôr em evidência a voz diferente ocultada do ponto de vista metodológico e inferiorizada do ponto de vista teórico. "Para as mulheres [diz a autora, 2003, p.03] espero que este trabalho ofereça uma representação de seu pensamento que lhes permita ver melhor sua integridade e validade". Invocando a lógica patriarcal ${ }^{4}$, Gilligan argumenta que a voz diferente é silenciada e inferiorizada em vista de uma estrutura social, política e epistêmica que privilegia o homem e as características a ele associadas. A voz das mulheres é diferente em virtude de ocupar um lugar contra-hegemônico e marginalizado. Gilligan pretende enfatizar que, do ponto de vista das éticas da justiça, o diferente é visto como inferior, o que gera certa 
debilidade na propagação e entendimento de uma ética pressuposta a partir do aporte de experiências ditas femininas.

Conforme observa Gilligan (2003, p.02), o pressuposto central de sua pesquisa é "que a forma como as pessoas conversam sobre suas vidas é importante, que a linguagem que elas usam e as conexões que fazem revelam o mundo que elas veem e no qual agem”. Esse é um ponto que converge para a tese de que homens e mulheres tem experiências morais distintas e que a moral (da justiça) se concentra nas experiências masculinas frente aos dilemas morais. A voz padrão é referenciada como masculina ao passo que a voz diferente é relacionada com a mulher, o que denota que homens e mulheres detém diferentes modos de problematizar situações na esfera da moralidade bem como orientar e tomar as suas decisões.

A tese de Gilligan ganhou seu segundo "teste" empírico 5 junto ao trabalho de Nona Lyons, cujo resultado foi apresentado no texto Two Perspectives: On Self, Relationships, and Morality (1983). Segundo Lyons (1983, p.127),

Gilligan sugeriu que as concepções de self e moralidade podem estar intrinsecamente ligadas. Em suma, Gilligan apresentou as seguintes hipóteses(1) que existem dois modos distintos de julgamento moral - justiça e cuidado - no pensamento de homens e mulheres; (2) que estes são relacionados ao gênero; e (3) que os modos de julgamento moral podem ser relacionados a modos de autodefinição.

Lyons apresenta a pesquisa que pretende fundamentar a vinculação entre identidade e percepção moral, ou seja, a ideia é apresentar que o modo como as pessoas se concebem (veem a si mesmas) influencia no modo como percebem a moralidade. A entrevista contou com 36 pessoas: homens e mulheres de faixas etárias variadas. As questões apresentadas nas entrevistas e que basearam a sua análise foram as seguintes: “o que a moral significa para você?" e "como você se descreveria?”. Lyons (1983, pp.125-126) aponta que os resultados convergem no sentido de admitir que os homens concebem a moralidade nos termos de justiça, traduzida sob a rubrica de a coisa certa a fazer, enquanto que as mulheres percebem a moralidade em termos de sensibilidade e responsabilidade, traduzindo, portanto, uma perspectiva de cuidado. Dentro da afamada bandeira homens da razão e mulheres da emoção, Lyons (1983, p. 127) observa que há uma convergência entre o modo de perceber a moralidade e o modo de se autodefinir. Há uma regularidade na percepção dos homens acerca de si mesmos nos termos de "separado e objetivo" enquanto as mulheres se autoidentificam com um self "conectado e interdependente em sua relação com os outros". 
A obra de Gilligan, embora seja referência necessária quando se pretende tratar de uma, por assim dizer, "arqueologia do cuidado", foi e ainda se mantém alvo de muitas críticas. Embora Gilligan (2003, p.02) afirme: “A voz diferente que descrevo é caracterizada não por gênero, mas por tema. A sua associação com as mulheres é uma observação empírica, e é principalmente através das vozes das mulheres que eu traço seu desenvolvimento", as críticas apontam que a autora, na verdade, tende a defender uma moral própria e oriunda (da pressuposição) de uma lógica estritamente feminina. A grande maioria das críticas, em maior ou menor grau e mobilizando distintas abordagens argumentativas, convergem, portanto, para a sustentação de certo essencialismo de gênero, a saber, de que homens e mulheres possuem diferenças inexoráveis que repercutem, inclusive, no modo a partir do qual percebem e dirigem questões morais. Joan Scott (1989, p.18), por exemplo, observa que "a sua noção é a-histórica, definindo a categoria mulher/homem como uma oposição binária que se autorreproduz, estabelecida sempre da mesma forma".

A separação entre homens e mulheres em eixos distintos de percepção e reação moral resulta também em certa homogeneidade das mulheres entre si e dos homens perante os homens de modo a desconsiderar fatores não generificados (como raça, classe e etnia) que possam afetar no modo dos indivíduos pensarem a si mesmos e a moralidade. O fato é que Gilligan parece não só compartimentar os homens e as mulheres dentro de uma perspectiva binária como também engessa suas percepções morais. Isso acaba redundando na legitimação de que homens e mulheres são realmente diferentes, reforçando um tipo de pensamento biologista que as feministas buscam combater ${ }^{6}$.

Gilligan (2011, p.41), contudo, procura desconstruir tais críticas argumentando que o vínculo direto entre a mulher e o cuidado só faz sentido num contexto de estereótipos e divisão dos papeis de gênero como o que vivemos:

Em uma sociedade e uma cultura patriarcal, o care é uma ética feminina, que reflete a dicotomia do gênero e a hierarquia do patriarcado. Em uma sociedade e uma cultura democráticas, fundadas sobre a igualdade de vozes e o debate aberto, o care é uma ética feminista: uma ética que leva a uma democracia liberada do patriarcado e dos males que lhe são associados, o racismo, o sexismo, a homofobia, e outras formas de intolerância e de ausência do care.

Assim, somente em contextos sociais em que mulheres são identificadas com o cuidado é que se compreende a ética do cuidado como feminina. Gilligan põe em destaque certa 
deformação de valores oriundos da separação de pessoas e papéis de gênero. A voz diferente vem, justamente, no sentido de romper com dualidades e hierarquias, se constituindo, no domínio de uma sociedade pós-patriarcal, em uma voz humana.

Com efeito, isso parece não resolver de todo a questão, quer em vista de que muitos críticos observarem uma defasagem entre declarações de Gilligan e a essência de seu texto, no sentido de que sua "defesa" não coincide com noções básicas de sua teoria em sua obra seminal, a qual sugere que mulheres se concebem e agem segundo paradigmas distintos pelo fato de serem mulheres, quer em vista da fragilidade dos dados mobilizados em vista da fundamentação da chamada voz diferente. Sob esse segundo aspecto, é notório que a partir de uma pequena amostra tanto Gilligan quanto Lyons intentem defender tão impactante e vigorosa tese.

Segundo Scott (1989, p.18), “Gilligan e outros extrapolam sua própria descrição, baseados numa pequena amostra de alunos americanos do fim do século XX para todas as mulheres". Gilligan, por exemplo, a propósito de uma entrevista na qual apresenta os dilemas morais hipotéticos, menciona o seguinte fato: "Ela me olhou e disse: você quer saber o que eu penso ou você quer saber o que eu realmente penso?, assinalando que ela teria aprendido a pensar de um modo diferente daquele que ela pensa na realidade" (GILLIGAN, 2011, p.40). Percebe-se, com efeito, que Gilligan se apoia em dados muitos frágeis e pouco reveladores quando pensamos, por um lado, em uma pequena amostra em termos quantitativos e, por outro, o caráter da vivência dessas pessoas que representam um segmento dentro uma sociedade caracterizada por padrões hegemônicos. Gilligan pretendeu, portanto, defender os diferentes sensos morais de homens e mulheres a partir da experiência de jovens americanos situados em condições bem diferentes da maioria dos jovens do mundo quando pensamos a oposição do norte e do sul global. Contudo, é forçoso reconhecer que a acessibilidade da tese de Gilligan também foi o grande vetor do seu sucesso em termos de visibilidade. Raewyn Connel e Rebecca Pearse (2015, p.138) se referem a tese de Gilligan como "uma adaptação feminista mais simples da psicanálise e da psicologia do desenvolvimento", "uma versão branda do feminismo". O fato é que a linguagem acessível e o raciocínio simplista tornam a leitura da obra e o entendimento da tese cativantes uma vez que endossam noções de fácil trâmite junto ao senso comum. Tratase, portanto, de um feminismo brando porque não rompe com pressupostos básicos que caracterizam o que cotidianamente se define como masculino e feminino.

Em crítica a Gilligan, Marilyn Friedman (2011, p.85) observa que 
a moralização do gênero está mais relacionada com o modo que nós acreditamos raciocinar do que como nós propriamente raciocinamos - mais com preocupações morais que nós atribuímos aos homens e às mulheres que com as verdadeiras diferenças estatísticas existentes entre o raciocínio moral de homens e aqueles de mulheres.

Gilligan, portanto, construiu uma investigação cuja ideia seminal povoa o imaginário popular por carecer de grande aporte teórico. Assim, pode-se afirmar que Gilligan incorreu no erro propagado por Descartes nas Meditações (1979, p.85) de tomar o provável por certo, edificando uma teoria cuja base está imersa em crenças e dúvidas. Isso, com efeito, não impediu a fertilidade da tese de Gilligan respaldada quer no que tange ao lugar da mulher enquanto sujeito epistêmico, em que se destaca o aspecto androcêntrico da produção de conhecimento, quer para aqueles que endossam sua investigação da gramática do cuidado ancorada no gênero, ou, ainda, para aqueles que, a partir de suas teses e buscando transpô-las ao modo de uma crítica ou superação, encontraram "na voz diferente" motivação e entusiasmo teórico.

II -A crítica de Tronto: o cuidado vinculado a condições de subordinação

Diferentemente da interpretação atribuída à Gilligan, Tronto não trata do cuidado sob a perspectiva de diferenças de gênero, mas da pertinência da sua reflexão acerca do cuidado enquanto uma teoria vinculada às condições de subordinação inerente à sociedade moderna. Tronto observa que "sugerindo que a ética do care está ligada ao gênero, Gilligan exclui a possibilidade de que o care seja uma ética criada na sociedade moderna por certas condições de subordinação" (TRONTO, 2011, p.53). Sob esse aspecto, a voz diferente associada as mulheres pode estar vinculada a qualquer grupo que esteja socialmente subordinado. Entender a especificidade do cuidado pressupõe e passa, portanto, por uma teoria política e social. O que Tronto implicitamente parece dizer é que há um deslocamento, dentro da análise de Giligan, entre a formação teórica do cuidado e o cuidado enquanto prática.

A tarefa incluiria tomar criticamente a noção de moralidade das mulheres proposta pelas interpretações das investigações sobre a moral e as distinções por gênero, e situar essas interpretações no contexto das investigações sobre a moralidade e as distinções de classe, raça e etnia (TRONTO, 1987, p.6). 
Portanto, a "voz diferente" por Gilligan vinculada a uma moral da responsabilidade e do cuidado não está restrita às mulheres, mas pode ser verificada no discurso e ações de grupos não-hegemônicos em geral. Assim o acento é transferido de uma causalidade psicológica para uma causalidade social, cuja maior implicação recai numa significativa ampliação da reflexão acerca do cuidado. Tronto defende uma maior teorização e ampliação da teoria do cuidado a fim de analisá-la para além do paradigma do gênero, embora ainda o compreenda.

O cuidado para além do gênero

Dentro do que poderia ser denominado de uma perspectiva interseccional do cuidado, Tronto apresenta novos modos de investigar a questão. Ela alarga os princípios de reflexão de Carol Gilligan ao enfatizar que o trabalho de cuidado pode estar vinculado ao feminino, mas vem, comumente, também associado a outras intersecções. "Na maior parte das sociedades [diz Tronto (2009, p.20)], as funções que se relacionam com o care são distribuídas por gênero, por casta e por classe, e frequentemente também o são por raça e etnia". O fato é que o forte destaque ao gênero pode obscurecer a questão de classe e raça.

ninguém examinou os membros de grupos minoritários usando a metodologia de Gilligan para ver se suas perspectivas são melhor descritas pela ética do cuidado que pelas categorias de Kohlberg. A pesquisa do aborto de Gilligan, como o trabalho de Kohlberg, têm a limitação de se concentrar apenas nas pessoas de classes avantajadas (TRONTO, 1987, p.6).

Inclusive, Tronto faz referência (2011, p.56) a estudos que abordam diferentes níveis de desenvolvimento moral entre crianças brancas e negras, os quais apontam que as primeiras apresentam concepções morais mais avançadas dentro da referência de paradigmas morais hegemônicos. Em outro estudo mencionado, Tronto (2009, pp.120-121) observa que entre grupos menos privilegiados, a diferença de gênero quanto a abordagem moral geralmente não aparece e, quando aparece, é pouco significativa. Sandra Harding (1987), inclusive, desenvolve uma profunda investigação acerca da semelhança entre a moral dita feminina e a moral africana, reflexão que endossa a crítica de Tronto a Gilligan quer no que tange ao essencialismo quer no que se refere ao localismo de sua abordagem.

Tronto observa que vários dados sugerem que membros de grupos não hegemônicos cultivam a mesma lógica moral por Gilligan atribuída às mulheres. Ou seja, tais grupos são 
melhor caracterizados por uma ética do cuidado do que por uma ética da justiça. São forças sociais, portanto, que engendram a diferença da abordagem moral das mulheres e de grupos não hegemônicos em geral. A experiência cotidiana de desrespeito, penúria e exclusão, associadas entre si ou não, resulta em modos distintos de senso moral.

Tronto não nega que o gênero constitui influência na formação do pensamento moral. Conforme observa a autora (2009, p.98), a moral não se constitui como um domínio distinto e autônomo da atividade humana, mas resulta de práticas cotidianas contextuais e historicizadas. Nesse sentido, se pretende assinalar que o gênero é apenas uma das dimensões a partir das quais a moral pode ser concebida. A pretensa universalidade opera no sentido de legitimar um sujeito que será considerado como moralmente competente. Os membros dos grupos não-hegemônicos não são propriamente caracterizados como outros, no entanto, são invisibilizados à proporção que absorvidos pelo modus operandi hegemônico sob a rubrica da universalidade.

Enquanto Gilligan supõe gênero como a única categoria pertinente da diferença, Tronto concebe o cuidado dentro de uma perspectiva social, a qual denuncia que a disposição moral está vinculada a uma posição de subalternidade social. Embora mantenha a questão de gênero, uma vez que as mulheres constituem um grupo socialmente subalterno, Tronto invoca operadores sociais que permitam não apenas distinguir as experiências morais de homens e mulheres, mas das mulheres e dos homens entre si.

O cuidado se converte em uma categoria de análise política quando procura desvendar e pôr em destaque as relações de poder e hierarquia inerentes ao cuidar. Ele aparece quer como indicador de desigualdades na forma das hierarquias estruturais de raça e gênero quer como referência na distribuição de cuidado na forma de acesso a bens básicos de uma vida digna, em que se realça seu valor político de reestruturação social. Tratar o cuidado como uma disposição e/ou atividade de pouca importância social ou como uma atividade que (com algumas exceções $^{7}$ ) não requer grande preparo vem no sentido de manter fixa a estrutura que desvaloriza os prestadores de cuidado.

Segundo Tronto, mesmo que se admitisse a validade e legitimidade da concessão de um gênero à voz diferente, a questão seria altamente problemática quando se toma em consideração as implicações políticas e sociais daí resultantes. Dotar a voz diferente de um gênero implica assimilar a identidade dos diferentes, ou seja, identificar homens e mulheres como distintos e dotados de aptidões próprias de cada gênero. Muito se afirmou e ainda se defende que a admissão das mulheres na política, por exemplo, mudaria a política, uma vez que traria uma 
abordagem diferenciada em vista da composição da experiência feminina com o cuidado. $\mathrm{O}$ problema inerente a esse tipo de posicionamento, aparece, segundo Tronto (2009, p.126), imediatamente: "ele conduz a uma espécie de <<crypto separatismo $>>$, quer dizer, que a participação das mulheres na vida política ou moral resta claramente delimitada”. Mesmo a afirmação de Gilligan de que mulheres e homens devem partilhar da voz diferente em vista de relações mais humanas, resta problemática em vista de que, embora defenda que todos (homens e mulheres) devam aderir à ética do cuidado não modifica, por si mesmo, o valor prático e teórico da ética do cuidado perante a ética da justiça ${ }^{8}$.

O que resta como necessidade iminente, enfim, é um maior embasamento teórico da ética do cuidado. A mudança requer alteração nos termos do debate. É isso que Tronto faz relativamente ao cuidado. A questão fundamental, contudo, se centra na razão pela qual esse tipo de abordagem ainda persiste. Tronto é categórica em sua resposta:

uma moral concebida a partir do gênero contribui para manter do mesmo jeito a distribuição de poder e de privilégios segundo as linhas de compartilhamento não somente de gênero, mas também de classe, de raça, de etnicidade, de educação e outros (TRONTO, 2009, p.132).

Tronto, portanto, identifica no discurso da moral das mulheres uma fonte de manutenção de poder quer relativamente ao gênero quer no que tange às intersecções de classe, raça e etnia. Endossar esse tipo de discurso resulta na manutenção da esfera de poder que oprime (em maior ou menor grau, direta ou indiretamente) mulheres, pobres e pessoas de cor.

A partir da relação entre saber e poder, Foucault (1996) defende que a verdade corresponde a um conjunto muito bem articulado de regras que exclui e inclui discursos de saberes. A inclusão e exclusão obedece a um controle e enquadramento, de maneira que o saber não é neutro, mas "aparece" no sentido de engendrar técnicas disciplinares e manutenção de poderes $^{9}$. Na questão que toca essa investigação, a manutenção de poder atende tanto a princípios patriarcais, na forma do essencialismo da mulher como uma figura de cuidado e zelo, quanto à manutenção de privilégios de raça, classe e etnia eclipsadas na perpetuação e legitimação de atividades de cuidado que são subalternizadas no interior da vida social. 
Essencialismo, elitismo e relações de poder

Destacando a intersecção de classe, raça e etnia, Tronto pretende demonstrar que a experiência moral das mulheres, longe de ser homogênea, é perpassada por hierarquias que a conduzem e conferem características próprias que dependem do espaço social que atuam. Gilligan apresenta na sua análise mulheres que ocupam posições privilegiadas na sociedade como se elas representassem a totalidade das mulheres e suas perspectivas diferentes. Dentro de uma perspectiva essencialista, ela define as mulheres (seus interesses e dons) a partir do cuidado, reforçando o estereótipo do zelo e do afeto como características femininas. Dentro de uma perspectiva elitista, ela, por um lado, apresenta o modelo do cuidado tomando como exemplo mulheres (universitárias) que devido suas condições de existência não estão diretamente atreladas ao cuidado ${ }^{10} \mathrm{e}$, por outro, torna homogênea a experiência das mulheres em geral tomando como referência o padrão de mulheres que analisou.

Quanto à questão do vínculo da mulher com a afetividade, é interessante notar que, embora Gilligan identifique a ética do cuidado como uma ética das mulheres mobilizando questões relativas a atenção amorosa, o sentimento enquanto uma característica eminentemente feminina é algo relativamente recente. Considerando a ética sentimentalista nos nomes de Hume, Hutcheson e Smith, a capacidade de ser tocado perante a situação de um terceiro se constitui na qualidade do homem (masculino) virtuoso. A atribuição de um gênero aos sentimentos morais ocorreu, conforme Tronto (2009, p.90), no decorrer do séc. XVIII como uma forma de reação em vista da reivindicação das mulheres em desempenhar funções no espaço público. Isso resultou na ideia de que o lugar natural da mulher está vinculado ao cuidado dos filhos e diligência do lar. Isso foi de tal modo impregnado na compreensão das mulheres acerca de si mesmas que as próprias sufragistas, na odisseia da luta pelo voto, bradavam emocionadas que o direito de decidir sobre os rumos da sua sociedade as tornariam mais satisfeitas e, desse modo, mais dedicadas como esposas e mães. Daí que muitas delas se apresentaram vestindo a indumentária invisível de guardiãs da moralidade, da fraternidade e dos bons costumes e que sua atenção e afetividade representariam benefício na política (Cf. MILLET, 1970; DAVIS, 2016). Ocorre que o rebote se deu prontamente: os homens acreditavam que a dura e disputada vida pública acabaria por macular a sensibilidade e moral característica das mulheres. Kate Millet, nesse sentido, aponta três paradoxos inerentes à consideração das mulheres no período sufragista: proteção marital x desconsideração legal (1970, pp.17-18); feminilidade x trabalho em condições desumanas (1970, pp.20-21), castidade 
x legalização da prostituição (1970, p.22). O segundo deles retrata justamente a contradição inerente à justificativa da não inserção da mulher no mundo política: elas se tornariam menos delicadas e femininas. Ocorre, contudo, que já nesse período as mulheres trabalhavam como operárias ao lado dos homens e a perda da feminilidade nunca foi invocada como um empecilho para a execução de suas atividades laborais ${ }^{11}$.

Dois pontos aqui são fundamentais: primeiro, o aparente reconhecimento da chamada feminilidade das mulheres atua como um meio de opressão mascarado de enlevo; outro, a feminilidade obedece à certa instabilidade, uma vez que é vista como empecilho na execução de determinadas tarefas dentro de uma lógica de interesse marcada pelo sistema classe e raça. O essencialismo perpetua, por um lado, um engessamento da persona da mulher e, simultaneamente (de modo incoerente), obedecendo as hierarquias da classe e raça, reescreve esse engessamento como pertencentes a algumas mulheres e não todas. Linda Nicholson (2000, p.20), observa, a propósito de Gilligan, uma tendência à uniformidade: "Dizer que 'as mulheres são diferentes dos homens desse ou daquele jeito' é dizer que 'as mulheres são desse ou daquele jeito"”.

Daí a questão do elitismo que foi incorporado por Gilligan à ética do cuidado. Conforme Tronto, "ao longo da história americana, o argumento da $<<$ moralidade das mulheres $>>$ foi particularmente reservado às mulheres brancas, americanas de nascença, pertencentes à classe média" (TRONTO, 2009, p.125). A, por assim dizer, contraprova à tese da moral das mulheres (enquanto portadoras de uma voz diferente) é empregada por Tronto em vista de estudos que mostram que a ética do cuidado não aparece segundo o gênero, mas, sobretudo, face à condições de subordinação. É curioso, inclusive, que mesmo mantendo-se na categoria "gênero", o modelo adotado por Gilligan seja aquele da mulher branca e de classe média. Isso, sobretudo, à medida que consideramos que, enquanto agentes de cuidado, são as negras e imigrantes que se destacam. Nesse sentido, e parafraseando Bell Hooks (2015, p.193) que diz que "o feminismo não surgiu das mulheres que são mais vitimizadas pela opressão machista”, pode-se dizer que o cuidado foi pensado na teoria de Gilligan não sob o aporte e a experiência daqueles que mais diretamente lidam com ele. Tão atenta em distinguir a percepção moral das mulheres frente à percepção moral dos homens, Gilligan, distinguiu os homens das mulheres, mas não as mulheres entre si. Angela Davis (2016, p.135), a propósito das mulheres negras, afirma que "o que diferenciava essas mulheres das líderes das agremiações brancas era a sua consciência sobre a necessidade de contestar o racismo". Juntamente com a categoria raça; classe, etnia e orientação compõem o amplo repertório existencial a partir do qual as pessoas percebem o 
mundo e a si mesmo no mundo. Essa dimensão interseccional é fundamental a fim de não se recair em teses limitadas com pretensão de universalidade.

Trata-se da expansão e universalização de um modo branco e elitista de pensar que não encontra ressonância junto à outras culturas. Diante do chamado dilema de Heinz (de um homem roubar ou não um remédio que amenizaria a dor ou até salvaria a vida da esposa), as "mulheres de Gilligan" procuraram contornar a situação de modo a não cometer o delito. Bem, isso pode ser mais palatável para sujeitos que não experimentaram de modo profundo a escassez, a penúria e a necessidade, mas a assertiva ao roubo pode encontrar forte adesão em mulheres pertencentes a grupos marginalizados. Por outro lado, ainda, os homens desses grupos, devido ao compartilhamento da exclusão e do preconceito, podem ser mais solícitos e empáticos do que o homem branco de classe média, configurando-se, assim, em sujeitos portadores da voz diferente. Na teoria de Gilligan, o gênero é instrumentalizado no sentido de defender uma experiência comum quer às mulheres entre si quer dos homens entre si. Com efeito, esse é um modo de pensar que atende ao perfil da pessoa branca pertencente ao norte global, que não necessariamente encontra ventilação em outras vivências culturais, territoriais, econômicas e raciais.

\section{Considerações finais}

O que encontramos em Gilligan, a partir do lume da crítica de Tronto, é, enfim, uma abordagem elitista que pretende universalizar impressões de um grupo social seleto bem específico. Sob esse aspecto, assim como Gilligan questionou o modelo "masculino" pretensamente universal da ética, acabou, por assim dizer, por promover o modelo hegemônico de classe como modelo universal. Ainda deve ser dito que a teoria de Gilligan encontra a sua força e amparo em paradigmas sexistas inerentes à sociedade patriarcal. Sob esse aspecto, é inegável que parte de seu sucesso se deve ao fato de não transpor noções caras à adeptos a estereótipos de gênero. Ou seja, Gilligan mantém intacta a identificação das mulheres com o cuidado atendendo a expectativas do senso comum de compreensão da "natureza feminina" como sendo mais propensa e apropriada ao cuidado.

Tronto pretende destacar e trazer para a reflexão um modelo de cuidado que guarde como paradigma central a causalidade social e, não, dimensões psicológicas. O que Gilligan 
denomina de moral feminina é traduzido por Tronto como resultado da posição social de subordinação da mulher. Tomando a reflexão de Tronto como consistente (e parece bem sólida), resta que a ética do cuidado é mais fértil quando discutida como um fenômeno inerente a grupos não hegemônicos marcados pela intersecção do que como uma reflexão ancorada unicamente no gênero. 


\section{Notas:}

${ }^{1}$ Professora Assistente IV na Universidade Franciscana (UFN), Santa Maria, Rio Grande do Sul, R.S., Brasil. Email: leticiamspinelli@gmail.com

${ }^{2}$ Ao longo do texto, o leitor poderá observar que, por vezes, o termo care aparece sem tradução. Isso se deu em vista de que algumas traduções francesas aqui utilizadas mantiveram o termo original em inglês. Optou-se por respeitar a lógica dessas traduções.

${ }^{3}$ Aqui nos servimos da terceira edição, a qual conta com prefácio da autora, publicada em 2003.

${ }^{4}$ Kate Millet (1970) foi uma das primeiras teóricas a apresentar o patriarcado como um sistema de dominação do homem sobre a mulher dotado de um amplo espectro de poder: a organização do patriarcado se dá a partir de um esquema ideologicamente elaborado e socializado que envolve três categorias: o temperamento (componente psicológico), o papel (componente sociológico) e o status (componente político). O termo patriarcado antecede o seu uso na teoria feminista (sendo antes utilizado na teoria social por Weber)*, o qual se deu a partir da década de 70 pelas chamadas feministas radicais. Isso vem configurando, por parte de algumas autoras, a resistência em adotar tal terminologia. Pateman (1988, p.39), contudo, é a favor de manter o termo em vista de que ele representa "o único conceito que se refere especificamente à sujeição da mulher, e que singulariza a forma de direito política que todos os homens exercem pelo fato de serem homens". Adotamos aqui a definição de Saffiotti (1987, p.16): patriarcado com um "sistema de relações sociais que garante a subordinação da mulher ao homem". * Cf. WEBER. Sociology of religion. Boston: Beacon Press, 1964.

${ }^{5} \mathrm{O}$ primeiro foi configurado pelas próprias entrevistas feitas por Gilligan.

${ }^{6}$ A questão do determinismo biológico e construcionismo social impulsionou várias reflexões no domínio da chamada Segunda Onda do Feminismo. O determinismo biológico defende que constantes da natureza são responsáveis por constantes sociais; de modo que adotar o determinismo biológico significa barrar as contestações feministas por transformação. Daí a noção de construcionismo social, a qual defende que as identidades feminina e masculina não são oriundas de constantes da natureza, mas construídas e condicionadas socialmente mediante estereótipos de gênero que ajuízam os comportamentos adequados as mulheres e aos homens. Em sua obra Interpretando Gênero (2000), Linda Nicholson, questiona a forma com que a palavra "gênero" é usada e interpretada dentro da teoria feminista. A partir do chamado "fundacionalismo biológico" (NICHOLSON, 2000, p.4), termo criado pela própria autora para apontar que ainda subsistem resquícios de determinismo biológico junto à abordagem que se pretende construcionista social, Nicholson põe em crise a separação inicial entre sexo (tido como biologicamente dado) e gênero (socialmente construído). Essa questão, por si só, é bastante complexa e merece mais apuro. Oferecemos aqui apenas um indicador.

\footnotetext{
${ }^{7}$ É por suposto necessário reconhecer que socialmente foi tecida certa hierarquia do cuidado, na qual algumas ocupações são altamente valorizadas social e monetariamente em contraste com outras que são marginalizadas e legadas a grupos não hegemônicos.
}

${ }^{8}$ É interessante observar, embora essa questão não seja abordada aqui, que, diferentemente de Gilligan, Tronto
não desenvolve a sua argumentação sob a oposição entre justiça e cuidado, mas propõe uma reconfiguração da
justiça sob o aporte do cuidado. O argumento da contraposição entre justiça e cuidado, pressupõe uma relação
dicotômica em que o cuidado é particular e a justiça é universal, que o cuidado está vinculado à compaixão e a
justiça à racionalidade, que, enfim, o cuidado remete à relação e conexão enquanto a justiça opera dentro do
individualismo e da separação. "Nós defendemos a ideia [...] segundo a qual essa concepção de incompatibilidade
entre a justiça e o cuidado é inapropriada. Várias autoras feministas insistiram sobre o fato de que uma teoria do
cuidado é incompleta quando não inserida em uma teoria da justiça"(TRONTO, 2009, p.167). Aqui, novamente,
a defesa da coexistência das duas abordagens: "A ética do care é um conjunto de sensibilidades que toda a pessoa
moralmente adulta deveria desenvolver juntamente com as sensibilidades próprias da moral da justiça. No lugar
de repensar a filosofia moral, nós teríamos então a necessidade de mudar as instituições familiares ou educadoras
responsáveis de tornar as diferenças específicas ao gênero entre o care e a justiça. Nós deveríamos favorecer o
desenvolvimento das duas morais igualmente e deixar os indivíduos a atenção de decidir quando aplicar uma ou
outra" (TRONTO, 2011, pp.68-69).

9 “Suponho que em toda sociedade a produção do discurso é ao mesmo tempo controlada, selecionada, organizada e redistribuída por certo número de procedimentos que têm por função conjurar seus 
poderes e perigos, dominar seu acontecimento aleatório, esquivar sua pesada e temível materialidade" (FOUCAULT, 1996, pp.8-9).

${ }^{10}$ Obviamente toda a mulher está em alguma medida vinculada ao cuidado devido a sua socialização e, as mulheres entrevistadas por Gilligan, não representam uma exceção (tanto que a grande maioria referenciou o cuidado nas suas preocupações morais). Com efeito, as relações com o cuidado estão fortemente vinculadas com a posição de cada sujeito/grupo na sociedade podendo, portanto, estar mais próxima ou mais distante.

${ }^{11}$ Millet (1970, pp.20-21), inclusive, reproduz a resposta de uma operária chamada Rose Schneiderman à defesa de um senador de Nova Iorque de que as mulheres perderiam a sua feminidade se fossem portadoras de direitos humanos e civis: "Nas fundições há mulheres a trabalhar despidas até à cintura, por causa do calor. No entanto, o Senador nada diz quanto à perda de encanto destas mulheres [... ] claro que não ignoram que a razão pela qual as empregam nas fundições é que a elas pagam-lhes menos e trabalham mais do que os homens. Por exemplo, nas lavandarias, as mulheres estão em pé durante treze ou catorze horas, sob um vapor e calor terríveis, com as mãos mergulhadas em goma quente. Certamente que estas mulheres não perderão mais rapidamente a sua beleza e encanto pelo facto de votarem uma vez por ano do que pelo facto de permanecerem nas fundições e lavanderias durante todo o ano. Não há contenda mais violenta do que a contenda pelo pão diário, deixem que vos diga". 


\section{Referências}

CONNEL, Raewyn; PEARSE, Rebecca. Gênero: uma perspectiva global. Trad. e revisão de Marília Moschkovich. São Paulo: NVersos, 2015.

DAVIS, Angela. Mulheres, Raça e Classe. São Paulo: Boitempo, 2016.

DESCARTES, R. Meditações. Trad. de J. Guinsburg e Bento Prado Júnior. São Paulo: Abril Cultural, 1979/ Os Pensadores.

FOUCAULT, Michel. A ordem do discurso. São Paulo: Loyola, 1996.

FRIEDMAN, Marilyn. Au-delá du care: dé-moraliser de genre. In: LAUGIER, S. \& PAPERMAN, P. (dir.). Le souci des autres. Éthique et politique du care. Trad. de Bruno Ambroise. Paris: éd. de l'EHESS, 2011, pp. 79-102.

GILLIGAN, C. In a Different Voice: Psychological Theory and Women's Development. Cambridge: Harvard, Thirty-eighth printing, 2003.

. Une voix différent: um regard propectif à artir du passé”. In: LAUGIER, S. \& PAPERMAN, P. (dir.). Le souci des autres. Éthique et politique du care. Trad. de Bruno Ambroise. Paris: éd. de l'EHESS, 2011, pp.37-50.

HARDING, Sandra. "The curious coincidence of feminine and african moralities: challenges of feminine theory". In: KITTAY, F.; MEYERS, D.T. (Orgs). Woman and Moral theory. Rowman \& Littlefield. pp. 296-315, 1987.

HOOKS, Bell. Mulheres negras: moldando a teoria feminista. In: Revista Brasileira de Ciência Política, nº 16, Brasília, 2015, pp. 193-210.

LYONS, N. Two Perspectives: On Self, Relationships, and Morality (Vol. 53, n. 2). Harvard Educational Review, 1983.

MILLET, Kate. A política sexual. Lisboa: Dom Quixote, 1970.

NICHOLSON, Linda. Interpretando o gênero. Revista de Estudos feministas, Florianópolis, UFSC, vol. 8, $\mathrm{n}^{\mathrm{o}} 2,2000$.

PATEMAN, Carole. O contrato sexual. Rio de Janeiro: Paz e Terra, 1988.

SAFFIOTI, Heleieth I. B. O Poder do Macho. São Paulo: Moderna, 1987.

SCOTT, Joan. Gênero: uma categoria útil para a análise histórica. Trad. de Christine Rufino Dabat Maria Betânia Ávila. 1989. Disponível em https://edisciplinas.usp.br/pluginfile.php/185058/mod_resource/content $/ 2 / G \% C 3 \% A A n e r o-$ Joan\%20Scott.pdf. Acesso em: 28 de novembro de 2018.

TRONTO, Joan C. Más allá de la diferencia de género. Hacia una teoría del care. Traducción del Programa de Democratización de las Relaciones Sociales. Escuela de Posgrado. 
Universidad Nacional de General San Martín. In: Signs: Jornal of Women in Culture and Society, vol. 12, University of Chicago, 1987.

. «Au-delà d'une différence de genre. Vers une théorie du care». In: LAUGIER, S. \& PAPERMAN, P. (dir.). Le souci des autres. Éthique et politique du care. Trad. de por Bruno Ambroise. Paris: éd. de l'EHESS, 2011, pp. 51c-79.

TRONTO, Joan C.. Um monde vulnerable. Pour une politique du care. Avant-propos de Liane Mozère. Préface inèdite de l'auteure. Trad. par Hervé Maury. Paris: Découverte, 2009. 